\title{
0 método Getting Things Done (GTD) e as ferramentas de gerenciamento de tempo e produtividade
}

\author{
Mariana Alvim de Sá Pós-Graduanda em Gerenciamento de Projetos. Sesc Santa Catarina - Brasil. mariana-de-sa@hotmail.com \\ Abner Eutéquio Benício da Silva Pós-Graduando em Gerenciamento de Projetos - Brasil. abner.ebrs@gmail.com \\ Guilherme de Freitas Oliveira Pós-Graduando em Gerenciamento de Projetos. Blog Investidor de Sucesso - Brasil. guilhermemidiaon@gmail.com \\ Jane Aparecida da Silveira Pós-Graduanda em Gerenciamento de Projetos. Intelbras S/A - Brasil. janeminef@gmail.com
}

\begin{abstract}
RESUMO
Manter a produtividade elevada no meio de exorbitante quantidade de informações como ocorre atualmente, não é tarefa fácil. A dificuldade humana para gerir o tempo e tarefas, diante de uma lista de prioridades mal administradas muitas vezes fica evidente. Para colocar ordem na mente e deixá-la serena e livre para criar, David Allen desenvolveu o método GTD (Getting Things Done). Esse método conhecido mundialmente torna-se um grande aliado para implantação de um fluxo de trabalho gerenciável, sem muitas complicações e estresse. Este estudo foi baseado em pesquisas bibliográficas com abordagem qualitativa e descritiva, com objetivo de descrever os cincos estágios do método GTD elucidando o caminho para a prática e aplicação do próprio método. Como resultados, além da teoria do método, são apresentadas duas ferramentas disponíveis no mercado capazes de auxiliar na implementação do método. Como conclusões são apresentadas as características das ferramentas informatizadas e a importância do método para o gerenciamento de tempo e produtividade.
\end{abstract}

Palavras-chave: Getting Things Done. Produtividade. Gerenciamento de Tempo. Trello. Evernote.

\section{The method Getting Things Done (GTD) and time and productivity management tools}

\begin{abstract}
Keeping a high level of productivity amid the exorbitant amount of information we have today is not an easy task. The human difficulty to manage time and tasks, due to a poorly managed list of priorities is evident. To organize the mind and make it serene and free to create, David Allen developed the GTD (Getting Things Done) method. This worldwide known method becomes a great ally for deployment of a manageable workflow without many complications and stress. This study was based on bibliographical researches with a qualitative and descriptive approach, and has the purpose of describing the five stages of the GTD method elucidating the way to practice and apply the method itself. As a results, besides the theory of the method, two tools available in the market are presented. They enable the application of the method. As conclusion the characteristics of the computerized tools and the importance of the method for management of projects are presented.
\end{abstract}

Keywords: Getting Things Done. Productivity. Time Management. Trello. Evernote 


\section{INTRODUÇÃO}

A carga de tarefas assumidas pelos profissionais no dia a dia tem aumentado de forma intensa, assim como a complexidade delas, o que exige dos trabalhadores que, ainda durante a execução de uma determinada tarefa, já tenham que se programar para a tarefa que deverá ser feita a seguir. Quando nos é exigida concentração para executar uma demanda, seja na vida pessoal ou profissional, em grande parte das vezes falhamos porque parte da concentração exigida é utilizada para pensar em problemas diversos, enquanto outra é destinada ao que deveria realmente reter toda a atenção: a tarefa que estamos processando no momento.

Em busca dos questionamentos sobre o que, quando e como fazer, o americano David Allen criou um método que promete deixar a mente livre, relaxada e tranquila, com grande ganho em relação à produtividade, liberando espaço para que a criatividade possa fluir naturalmente.

O método criado é o Getting Things Done (GTD), conhecido no Brasil através do livro que tem o título "A Arte de Fazer Acontecer". O GTD consiste em uma série de passos que devem ser executados para que haja uma organização das tarefas diárias.

David Allen e alguns divulgadores do método GTD no Brasil como Daniel Burd e Thais Godinho, apresentam algumas ferramentas tecnológicas que dão importante suporte nos passos descritos no método. São ferramentas capazes de gerenciar tarefas e criar lembretes que facilitam na hora de organizar as atividades do dia a dia que tomam atenção. Essas ferramentas permitem mobilidade, pois podem ser acessadas de diferentes dispositivos (computador, notebook, smartphone, tablet, entre outros), proporcionando ganho significativo em relação a produtividade.

Esse estudo visa demonstrar as características e aplicabilidade do método GTD, algumas sugestões para a escolha da ferramenta a ser utilizada e como algumas delas implementam e auxiliam no fluxo de trabalho do próprio método.

O objetivo geral deste trabalho é analisar como funciona o método GTD, com foco na forma como ele auxilia as pessoas e organizações no processo de gerenciamento de tempo e produtividade, bem como sua implementação via ferramentas informatizadas.

Para o alcance do objetivo geral, foram definidos os seguintes objetivos específicos:

- Contextualizar bibliografia sobre gerenciamento do tempo e produtividade.

- Descrever os cincos estágios do método GTD para administrar o fluxo de trabalho.

- Analisar duas ferramentas que auxiliam na implementação do método, destacando algumas características e sugestões para a escolha das mesmas.

Tem sido cada vez mais notável a presença dos termos produtividade e gerenciamento do tempo nos ambientes organizacionais e na vida pessoal. São notáveis por terem a capacidade de gerar retornos positivos onde se almeja. $E$ sabe-se que é tarefa árdua se manter produtivo o tempo todo tanto quanto fazer o gerenciamento do tempo funcionar de modo eficiente. Existem dicas, técnicas, ferramentas e informações que tratam de propor como ter um bom gerenciamento do tempo para afetar de modo positivo sua produtividade.

Ao pesquisar tais termos, é difícil permitir que o método GTD passe despercebido, pois ele traz uma dinâmica capaz de dar certa fluidez em relação à execução e organização das atividades diárias. Allen fez um estudo vivenciado e bem explorado publicado em seu livro. O presente artigo justifica-se pela necessidade de explorar as temáticas produtividade e gerenciamento do tempo, de descrever um método capaz de simplificar a tarefa de gerenciamento de tempo sendo mais produtivo, além de analisar ferramentas que podem auxiliar na implementação do método.

De um ponto de vista acadêmico, o artigo se justifica por disponibilizar conhecimento científico sobre produtividade e gerenciamento de tempo, já que esses assuntos são escassos quando pesquisados em artigos, teses e outros materiais de cunho científico. Quando presentes, tais temáticas quase sempre são relacionadas a uma área específica, delimitando a quais situações elas se justificam como importantes.

Se tratando de modo geral, o artigo é disponibilizado a qualquer finalidade que possa tomar para si o conhecimento aqui construído, seja no ambiente acadêmico, organizacional ou pessoal.

\section{METODOLOGIA}

Neste capítulo apresentamos os aspetos metodológicos adotados para compreensão do método GTD.

Para Demo (1985, p. 19) "metodologia é uma preocupação instrumental. Trata das formas de se fazer ciência. Cuida dos procedimentos, das ferramentas, dos caminhos. A finalidade da ciência é tratar a realidade teórica [...]". Nesta perspectiva, o tratamento da realidade teórica pode ser visto como o exemplo aqui de conhecer uma técnica nova e fazer pesquisa a partir dela. Gil (2002, p. 17) também comenta que "a pesquisa é desenvolvida mediante o 
concurso dos conhecimentos disponíveis e a utilização cuidadosa de métodos, técnicas e outros procedimentos científicos".

Esta pesquisa é categorizada como qualitativa, pois o que o estudo propõe a verificar não é mensurável. De acordo com o Gerhardt e Silveira (2009, p. 31) "a pesquisa qualitativa não se preocupa com representatividade numérica, mas, sim, com o aprofundamento da compreensão de um grupo social, de uma organização, etc". Neste sentido, como qualquer busca para compreensão de um fenômeno, a pesquisa se reconhece como limitada e parcial, o que não significa sem rigor ou descompromissada.

Para a elaboração deste artigo procurou-se compreender como funciona o método Getting Things Done (GTD) e analisar duas ferramentas que implementam as características do método. Quanto ao procedimento técnico é uma pesquisa bibliográfica e quanto ao objetivo é descritiva.

No que se refere aos procedimentos, utilizou-se pesquisa bibliográfica para inteirar-se com o que já se produziu referente ao assunto pesquisado, isto vem ao encontro da conclusão de Marconi e Lakatos (2003, p. 183) quando afirmam que "sua finalidade é colocar o pesquisador em contato direto com tudo o que foi escrito, dito ou filmado sobre determinado assunto, [...] quer publicadas, quer gravadas".

Embora não tenha sido pretensão fazer uma pesquisa bibliográfica exaustiva sobre o método GTD, pelo fato de não se tratar de um conceito em formação, mas de algo que tem um criador e, portanto, serve de referência principal para a pesquisa, outros autores foram considerados. Assim, o caráter bibliográfico deste estudo busca, como todos deste tipo, informações em várias fontes, mas prioriza sobretudo a fonte original do criador do método GTD.

Vale destacar também a contribuição de Gil $(2002$, p. 44) que diz "embora em quase todos os estudos seja exigido algum tipo de trabalho dessa natureza, há pesquisas desenvolvidas exclusivamente a partir de fontes bibliográficas". No caso desse trabalho cabe destacar que não há exclusividade de fonte bibliográfica, pelo fato que a pesquisa fez também um percurso com o objetivo descritivo.

Deste ponto de vista, o estudo tem como objetivo descrever como funciona o método GTD. É tanto descritivo quanto interpretativo, cujas hipóteses apoiam-se na concepção de que a veracidade social não existe em um sentido concreto, mas isso sim é produto da subjetividade e experiências dos indivíduos e das organizações (MORITZ et al., 2010).

A perspectiva da descrição do método e da análise de duas ferramentas que o implementam, tem essa pretensão de mostrar como o GTD pode ser experimentado em diferentes softwares.

Igualmente Gil (2008, p. 48) ao analisar sobre pesquisa descritiva, aponta "as pesquisas descritivas têm como objetivo primordial a descrição das características de determinada população ou fenômeno ou, então, o estabelecimento de relações entre variáveis". O autor dá exemplo também de pesquisas que buscam verificar o nível de atendimento de uma instituição pública a uma comunidade.

O fenômeno estudado aqui é o próprio método GTD e as ferramentas que possibilitam sua implementação com o uso do computador e demais dispositivos.

\section{GERENCIAMENTO DO TEMPO, PRODUTIVIDADE E O MÉTODO GTD}

Para explicitar o método GTD, é importante que se faça a conexão entre dois temas importantes: gerenciamento do tempo e produtividade. Sabe-se que a capacidade de gerenciar de modo adequado o tempo, pode impactar na produtividade. Gerenciar o tempo disponível é um processo em que se deve planejar de forma adequada e mais realista possível, quanto tempo será gasto em cada atividade específica do dia. Um gerenciamento inadequado é geralmente acarretado por falta de planejamento do dia, da não utilização de uma agenda para gerenciar os compromissos, assumir mais tarefas do que de fato é capaz de executar, interrupções desnecessárias em meio a atividades, entre outros.

Já produtividade, tem a ver com o gerenciamento do tempo, mas não somente, pois, como mostra Sisi (2017) "identifica-se como produtivo o que fez mais, ofereceu um resultado maior ou melhor gastando menos [...] um profissional poderia ser considerado mais produtivo ao usar menos horas trabalhadas para entregar um volume específico de determinado trabalho." Para Sisi (2017), resumidamente significa produzir mais com menos, mas sempre atentando para que haja um equilíbrio, pois, produtividade também pode se tornar algo negativo. Por exemplo, um funcionário que faz muitas horas extras por dia está entregando produtividade para a empresa, mas e sua saúde? Seus relacionamentos? No caso desse artigo, a produtividade a qual se deseja alcançar é a positiva e equilibrada, e o método GTD propõe exatamente isso, entregar mais, economizando o tempo que se tem disponível através de um senso de organização. 
O método GTD foi criado por David Allen originalmente de um material que ele havia desenvolvido para palestras e treinamentos que ministrava e que acabou se transformando em um livro. O método visa entregar um gerenciamento de tempo equilibrado com boa produtividade, bem como o desenvolvimento do processo criativo, relacionado tanto ao aspecto profissional quanto ao pessoal. O GTD é capaz de oferecer um fluxo de trabalho de alta performance.

O método consiste basicamente em capturar todas as "coisas" que rondam a mente, sejam "coisas" a serem feitas ou algo que seja considerado útil, colocar essas "coisas" num sistema de confiança capaz de tirá-las da cabeça, se habituar a tomar decisões a respeito dessas capturas realizadas recorrendo a um sistema de "próximas ações" para executá-las em momentos oportunos, e por fim, organizar e coordenar todo o material capturado relacionando os níveis de comprometimento que eles implicam (ALLEN, 2015).

Para facilitar a implementação do método GTD e maior entendimento de sua organização, Allen (2015) o dividiu em 5 etapas: capturar, esclarecer, organizar, refletir e engajar.

As etapas, que devem ser implementadas na ordem que estão dispostas, são apresentadas nas seções seguintes.

\subsection{Capturar}

A fase capturar consiste em registrar tudo que estiver chamando sua atenção. Allen (2015) cita que é uma etapa que pode durar em torno de uma a seis horas, variando de pessoa para pessoa, assim como suas realidades.

Os itens a serem capturados, conforme apontados por Allen (2015) são todas as "coisas" que aparecem na cabeça, tudo que vier a memória, sem exceções. Essas capturas devem ser realizadas sem qualquer tipo de critério avaliativo, apenas os registros devem ser realizados, isso é suficiente para que elas parem de clamar por algum tipo de atenção, evitando que tempo e energia possam ser desperdiçados. Esses itens possuem laços abertos, ou seja, decisões e ações a serem tomadas a respeito, por isso existe essa preocupação de estar sempre lembrando de certas "coisas". Pode ser uma ligação pendente, uma visita a ser realizada, um relatório a ser feito, um item a ser consertado, entre outros (ALLEN, 2015).

Antes de começar o processo da captura, Allen (2015) evidencia a importância de preparar uma "caixa de entrada" física como bandejas de documentos de escritório, para que os itens capturados possam ser alocados dentro dela. Existem diversos softwares e aplicativos capazes de cumprir a tarefa de "caixa de entrada" conforme o método GTD solicita. Algumas delas serão abordadas em seções posteriores deste artigo.

Allen (2015), ao iniciar o processo das capturas, sugere iniciá-lo pelas capturas físicas, buscando no ambiente por tudo aquilo que esteja onde não deveria estar, "coisas" que necessitam de algum tipo de decisão a respeito. Todas essas "coisas" devem ser transferidas para a "caixa de entrada" para que sejam esclarecidas depois.

As "coisas" que não necessitam de ações, não devem ser colocadas na "caixa de entrada". Para tais itens, Allen (2015) define 4 categorias a fim de auxiliar na organização delas:

- Suprimentos - "coisas" que são utilizadas de forma regular como papéis, fita adesiva, clipes, formulários, elásticos e outros;

- Material de referência - tudo aquilo mantido para consultas, como manuais de instruções, cardápios, programações culturais, livros, números de telefones, lista de endereços, entre outros;

- Objetos decorativos - são itens de função decorativa como fotografias, placas, obras de arte, plantas, entre outros;

- Equipamentos - inclui o aparelho de telefone, computador, impressora, relógio, calculadora, caneta e outros mais.

Todos os itens que não demandam algum tipo de ação devem ser colocados em uma dessas quatro categorias anteriormente apresentadas, exceto em casos em que os itens destas categorias exijam que alguma ação deva ser feita a seu respeito por não estarem como deveriam estar. Por exemplo: a impressora que precisa de conserto, ou o relógio sem pilha, livros com conteúdo desatualizado e assim por diante. Nessas condições, esses itens precisam ser colocados na "caixa de entrada". Caso esses itens sejam grandes demais e não caibam na "caixa de entrada", é possível representá-los com uma pequena descrição, item por item, em folhas de papéis separadas, datadas e posteriormente alocadas na "caixa de entrada" (ALLEN, 2015).

Se algum item for visualizado em forma de lixo, recomenda-se descartá-lo imediatamente, desse modo muito tempo pode ser economizado e as gavetas limpas mais rapidamente. Se não tiver certeza sobre isso, coloque-o na "caixa de entrada" (ALLEN, 2015). Ao jogar alguma "coisa" no lixo, Allen (2015) sugere uma reflexão se tal item agrega algum desconforto ao ser descartado, se sim, é indicado que seja guardado, caso contrário é recomendando que se descarte, o importante é levar em consideração quanto de espaço existe disponível para isto. 
Allen (2015) indica que casos em que objetos encontrados forneçam alguma espécie de gatilho como "isso precisa ser resolvido imediatamente", uma reflexão sobre se estes objetos poderiam ir para a "caixa de entrada" é muito importante. Em caso positivo, eles devem ser colocados lá, caso eles não possam realmente esperar para serem processados é importante executá-los para que essa preocupação gerada por eles não atormente a mente ainda mais.

Feita toda a varredura pelo ambiente físico em busca de capturas de tudo que precisa de uma ação para ser resolvido, este é o momento de tirar tudo que se encontra dentro da mente que esteja tirando atenção quando não é o momento. Nesse caso, as capturas devem ser escritas em folhas de papéis, também uma a uma, em folhas separadas, bloco de papel ou aplicativos digitais. Tudo deve ser capturado: ideias, pensamentos, projetos, tudo que estiver chamando atenção de alguma forma deve ser capturado e colocado na "caixa de entrada" (ALLEN, 2015).

Para ajudar a esvaziar a mente e não correr o risco de algo ser esquecido, Allen (2015) indica fazer uma lista de gatilhos de pendências para que possam ser consultadas nesse processo sempre que necessário. É importante que nada deixe de ser capturado, por isso é ideal que sejam colocadas na "caixa de entrada" as mensagens de texto, emails e quaisquer outros itens que demandam ações (ALLEN, 2015). Feito todo o processo de captura, colocando os itens numa "caixa de entrada", é hora de esvaziá-la.

\subsection{Esclarecer}

Esvaziar a "caixa de entrada" não significa executar ações e projetos resultantes das capturas, mas sim, o esclarecimento do que é cada "coisa" capturada, o que significa e o que fazer a respeito (ALLEN, 2015). O autor indica estudar os processos esclarecer organizar antes de processar a "caixa de entrada", afirmando que dessa forma muitos passos são poupados.

Ao iniciar a fase esclarecer, Allen (2015) sugere que os softwares e hardwares que serão utilizados no processo, sejam previamente verificados para checar se estão funcionando de modo adequado. Após essa verificação é interessante que sejam criadas algumas categorias de trabalho como telefonemas, na rua, no computador, entre outras. Allen (2015) evidencia que as listas também podem ser feitas em folhas de papel ou qualquer material que dê para fazer listas, pois terão igual efeito dos softwares.

Para melhor aplicar o processo de esclarecer e esvaziar a "caixa de entrada", Allen (2015) estabelece algumas regras básicas, tais como começar pelo item que está por cima na "caixa de entrada", ou por último, mas continuar o processo pelos itens seguintes sequenciados como foram capturados, processar um item por vez, e por fim, nunca colocar um item de volta na "caixa de entrada".

Para que se crie uma sensação de segurança de que tudo o que precisa ser feito está devidamente registrado, é importante que a "caixa de entrada" seja limpa entre um a dois dias, além do mais, essa ação evita que surja uma necessidade de se checar o tempo todo o conteúdo do computador, celular e similares em busca de possíveis emergências (ALLEN, 2015).

Para auxiliar no processo, Allen (2015) sugere ainda uma pergunta chave: "Qual a próxima ação?". Segundo o autor essa decisão exige um raciocínio intenso e rápido, é fácil, porém pode não ser evidente e será necessário definila.

Pode acontecer de um item coletado não exigir algum tipo de ação, nestes casos Allen (2015) indica três destinos para estes itens:

- Lixo - o item pode ser destinado ao lixo, para tal decisão basta ter em mente o que precisa de uma ação para ser resolvido, o que é material de referência e suprimento, o que não se encaixa nessas categorias é lixo;

- Incubação - quando existe uma sensação em relação a algum item de que algo deve ser feito a respeito, mas não por agora, eles devem ser encaixados nesta categoria. Por exemplo, uma palestra, a pauta de uma reunião, atualização de um software, entre outros. Nesses casos é ideal que se crie uma lista "algum dia/talvez" e lembretes no calendário caso necessário. Dessa forma, esses itens são retirados da cabeça e deixará a sensação de conforto e segurança de que tal item irá aparecer quando for conveniente;

- Referência - aqui se encaixa tudo aquilo que não demanda uma ação, mas é útil a título de informação. O ideal é que se crie um arquivamento funcional para organizá-las. É importante etiquetar esses itens de referência e arquivá-los de modo que possam ser guardados ou consultados em um minuto. Vale também arquivar através de meios digitais.

Allen (2015) propõe que quando um item de fato demandar uma ação, uma definição exata de qual seria essa próxima ação deve ser decidida. Além do mais, é importante que a ação seja uma atividade física visível (uma ação que descreva um comportamento físico), que deve ser executada para que tal item seja dado como concluído (ALLEN, 
2015). Para auxiliar nas decisões sobre as ações, Allen (2015) indica que na grande maioria das vezes ter algumas informações e dados adicionais, como por exemplo opiniões externas, ou mesmo um raciocínio interno, pode ser de grande ajuda.

Quando as ações foram decididas, Allen (2015) propõe três alternativas para que elas sejam destinadas:

- Fazer - se realizar a "próxima ação" necessitar menos de dois minutos para ser concluída, elas devem ser feitas imediatamente, mesmo se não for urgente. Essa regra dos dois minutos gera um grande aumento da produtividade, pois o tempo gasto para arquivar e depois recuperá-lo é muito maior. Mas esses dois minutos podem ser estendidos para cinco ou dez minutos ou reduzidos para um minuto, dependendo da necessidade e tempo disponível para esses processos.

- Delegar - se a "próxima ação" demorar mais que dois minutos para ser concluída, é importante fazer uma reflexão se não seria mais adequado que outra pessoa fosse responsável por executá-la. Se sim, esta ação deve ser delegada de forma sistematizada, não sendo necessário delegar levando em conta a hierarquia de pessoas. O que deve ser levado em consideração na hora de delegar é o quanto a pessoa é a mais adequada para tal ação. É importante também que as ações delegadas sejam acompanhadas, para tal é possível colocá-las em uma bandeja separada de pendências.

- Adiar - se encaixam aqui todas as ações que duram mais de dois minutos para serem realizadas e que não têm como serem delegadas. É importante manter essas ações anotadas e organizadas em categorias específicas para que possam ser posteriormente melhor organizadas. Nesse primeiro momento elas podem ir para a bandeja de pendências, que mais tarde serão organizadas em um sistema pessoal.

Existe ainda uma última categoria especificada por Allen (2015) que é a de "projetos", sendo projeto tudo aquilo que se deseja concluir, mas que demanda mais de uma ação para ser concluída. Ou seja, se uma ação definida para um item capturado não for suficiente para alcançá-lo, ele é um projeto. É importante inclusive que lembretes sejam criados para lembrar as "próximas ações" a serem executadas dos projetos identificados (ALLEN, 2015). O autor também propõe que sejam feitas atualizações sempre que possível na lista de "projetos" revisando-a com frequência.

Entendido como funcionam as capturas realizadas e seu esclarecimento, é hora de organizá-las, conforme apresentada na seção seguinte.

\subsection{Organizar}

Nesta seção será apresentado o terceiro estágio do método GTD identificado como organizar: como definir os compartimentos certos (ALLEN, 2015). De início é interessante destacar que, de acordo com o autor, o objetivo é orientar sobre as etapas e ferramentas de organização necessárias à medida que as "coisas" vêm sendo processadas na "caixa de entrada".

A Figura 1 apresenta as listas que o autor sugere para organização, estas precisam ser acompanhadas e administradas.

Figura 1 - Diagrama do fluxo de trabalho
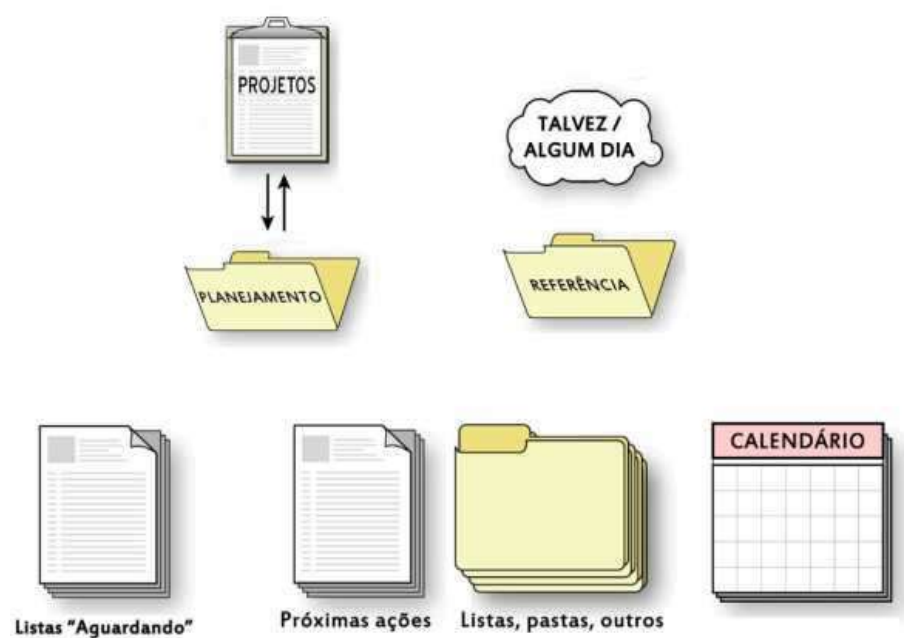

Fonte: Allen (2015, p. 30) 
Allen (2015) sugere a criação de listas e agrupamentos de "coisas" a serem organizadas e/ou realizadas à medida que as "coisas" passam pela triagem na "caixa de entrada". O sistema de organização automaticamente vai evoluir conforme as tarefas vão sendo processadas, consequentemente novos itens, grupos e listas a incluir surgirão.

O autor salienta ainda que para fins de organização, existem duas ações básicas: aquelas agendadas, ou seja, precisam ser executadas em um determinado espaço de tempo e aquelas instantâneas, que precisam ser realizadas o mais rápido possível. Como faz notar Godinho $(2014$, p. 90 ) "existe uma grande diferença entre uma tarefa como 'pagar a conta de luz que vence hoje' e 'organizar o armário' [...] uma realmente tem um prazo, a outra não. E somente aquelas que tem um prazo devem ser anotadas na agenda".

De acordo com Barbosa (2012), ausência de organização ao ser resolvida ajuda a aumentar a produtividade contanto que é mais simples executar as ações em ambientes organizados. Allen $(2015$, p. 124) comenta que "[...] ter um sistema de organização completo e contínuo, montado e funcionando, é algo que lhe dá um tremendo poder, porque permite à sua mente abandonar o raciocínio de nível inferior e se elevar até a concentração intuitiva [...]", ao referir-se a tal assunto Godinho $(2014$, p. 9) diz que "organização tem a ver com funcionalidade, não com beleza, aparência, limpeza, arrumação. Ser organizado é criar sistemas que facilitem o dia a dia. É possibilitar a arrumação".

Outra questão que Allen (2015) apresenta é a criação de categorias de lembretes de ação por meio de situações específicas e quantidade de ações embutidas nesse contexto (por exemplo: lista de telefonemas /no computador /ações no escritório /em casa). Essa forma de organização potencializa sua produtividade. Por exemplo, quando você organiza seu guarda-roupa, é melhor concluir maior número de tarefas relacionadas que puder, sem desviar o foco para outro tipo de atividade. Isso vem ao encontro da conclusão Levitin (2015, p. 49): "depois que você estabeleceu prioridades e começou a trabalhar, o fato de saber que aquilo que está fazendo é a coisa mais importante a fazer no momento [...] as outras coisas podem esperar - é nisso que você pode se concentrar sem se preocupar [...]".

Outro problema é a mistura de grandes volumes de dados e materiais que não estão associados a ações com elementos que requerem ações. Organizar adequadamente dados não passíveis de ação não interrompe o sistema de organização e se enquadram nas seguintes categorias: materiais de referências, materiais de suporte aos projetos e lembretes relativos a itens que não demandam ação (ALLEN, 2015).

Allen (2015) mostra a necessidade de organizar ou administrar também itens que se pretende revisar no futuro, por exemplo, viagem dos sonhos que se deseja realizar um dia, pós-graduação que se pretende fazer depois da graduação, projetos que se quer implementar nos próximos anos, entre outras, na mesma linha de raciocínio. Godinho (2014, p. 44) assegura que "ter esse controle do tempo é o que dá a sensação de dever cumprido e vida coerente, pois podemos fazer ajustes aqui e ali. É comum perceber que passamos os dias deixando de lado o que é importante [...]".

Neste sentido, a tarefa de organizar permite um melhor controle sobre os itens que precisam ser tratados. $\mathrm{O}$ próximo passo é refletir, apresentado na seção seguinte.

\subsection{Refletir}

De acordo com Allen (2001), o método GTD tem como intuito oferecer condições para que o usuário consiga avançar em suas atividades de forma mais produtiva possível. Para que uma determinada função seja bem desempenhada é necessário que o envolvimento com o trabalho em questão seja total e, por isso, revisar o processo constantemente se faz obrigatório.

Ao finalizar as etapas anteriores, o usuário do método se encontra em nível de conhecimento adequado de todas as suas atribuições determinando prioridades economizando assim tempo e esforço para desempenhar uma atividade específica.

Para chegar no verdadeiro conhecimento do processo, é necessária a revisão do mesmo, etapa esta que também deve ser feita com cautela e organização, para que a prática seja fácil e rápida (ALLEN, 2015). É importante saber identificar quais dados devem ser avaliados para a escolha do que fazer, no momento certo e com uma certa frequência para o processo se tornar mais dinâmico.

Este processo, como citado por Allen (2001, p. 141) "[...] não passa de senso comum, mas poucas pessoas têm realmente os seus processos e sua organização afiados ao ponto de serem funcionais à máxima capacidade.". Caso a realidade seja a mesma dos poucos que têm esta visão, a revisão será feita de forma rápida e fácil, demandando pouquíssima energia. $O$ autor cita que a revisão deve ser feita constantemente em todos os níveis, destacando o calendário como um item de primeira importância. 
Allen (2001) aconselha organizar listas e deixá-las sempre próximas, evitando gastos de energia desnecessária para realização da tarefa em questão, e reitera afirmando o quanto é necessário a periodicidade nesse processo na busca do equilíbrio.

O autor sugere a prática de um exercício simples para se chegar ao estado de envolvimento necessário para uma boa revisão:

- Papéis soltos

- Processe suas anotações

- Dados anteriores no calendário

- O calendário que vem por aí

- Esvazie a sua cabeça

- Revise as listas de "Projetos"

- Revise as listas de "Próximas ações"

- Revise a lista "Em espera"

- Revise todas as listas de verificação relevantes

- Revise a lista de "Algum dia/talvez"

- Revise a lista dos arquivos "Pendentes" e de apoio

- Seja criativo e corajoso.

Desta forma, "encare sua lista e analise o que pode — ou até deve! — ser feito imediatamente. Assim, a cada nova semana, revise essa listagem de afazeres para verificar seu progresso." (MARCON, 2015).

Realizada a reflexão das "coisas", a próxima etapa, intitulada como engajar, finaliza o método.

\subsection{Engajar}

Nesta última etapa para a implementação do método, Allen (2001) apresenta três formas distintas para ajudar nas decisões das ações a se desenvolver: o modelo de quatro critérios para escolher ações no momento, o modelo tríplice para avaliar o trabalho diário e o modelo em seis níveis para revisar o próprio trabalho.

\subsubsection{O modelo de quatro critérios para escolher ações no momento}

Com base em quatro critérios, Allen (2001) demonstra como tirar o máximo proveito da dinâmica criada pelo usuário do método:

- Contexto - são as escolhas de tarefas que podem ser executadas no local onde o usuário está e com as ferramentas que possui, essas listas evitam reavaliações desnecessárias, pois permitem consulta rápida das tarefas permitidas no ambiente em que o usuário se encontra. Por exemplo: na rua, no escritório, telefonemas, em casa, entre outras;

- Tempo disponível - disponibilidade de tempo para executar a ação;

- Energia disponível - ação no qual o indivíduo tenha energia pessoal para executá-la;

- Prioridade - dado o contexto, tempo e energia disponível, o autor sugere fazer a seguinte indagação: de tudo o que ainda resta ser feito, qual é o mais importante?

\subsubsection{O modelo tríplice para avaliar o trabalho diário}

O ato de priorizar, nem sempre é algo intuitivo. Allen (2001) nota que o indivíduo em algum momento do dia se envolverá com uma dessas três atividades:

- Fazer trabalhos predefinidos - são as "coisas" pontuadas na agenda, nas listas de "Tarefas", listas de "Próximas ações", "Projetos". Esses itens quando pontuados permitem serem negociados (GODINHO, 2017).

- Fazer os trabalhos na medida que aparecem. Godinho (2017) resume muito bem como as demandas do dia, imprevistos ou urgências. Allen (2001) ressalta que deixar-se envolver pelas urgências sem estar confortável com as "coisas" com as quais não está lidando gera frustração e ansiedade.

- Definição do trabalho - momento para organizar as listas e coletar novas "coisas" para as listas. Godinho (2017) reforça que para ser produtivo é necessário investir tempo na organização. 


\subsubsection{O modelo em seis níveis para revisar o próprio trabalho}

Allen (2001) apresenta uma metáfora com a aviação para as prioridades humanas:

- Decolagem: ações atuais - nessa etapa o usuário do método deve se ocupar com as listas de ações, deixar tudo registrado, todas as "coisas".

- 10 mil pés: projetos atuais - o autor afirma que ter a lista de "Projetos" atualizada permite abrir o campo da visão, permite que as pessoas descubram que há "coisas" que podem ser feitas para dar continuidade aos projetos.

- 20 mil pés: áreas de responsabilidade -criar uma lista chamada "Área de foco"; será menos revisada do que a lista de projetos, por se tratar de uma lista de estímulos a novos projetos em potencial.

- 30 mil pés: metas para um ou dois anos.

- 40 mil pés: visões para três a cinco anos.

- 50 mil pés ou mais: vida - para esses últimos níveis, Allen (2001) os reúne por se tratarem de aspectos profundos do ser humano. Devem ser registradas as estratégias de negócio, planos para desenvolvimento organizacional, planejamento de carreira e direcionamento de vida e valores.

\subsection{Articulação entre as etapas do método}

Uma forma esquemática do Método é apresentada pelo próprio criador, conforme apresentado na Figura 2.

Figura 2 - Fluxo do Método GTD

\section{COISAS}

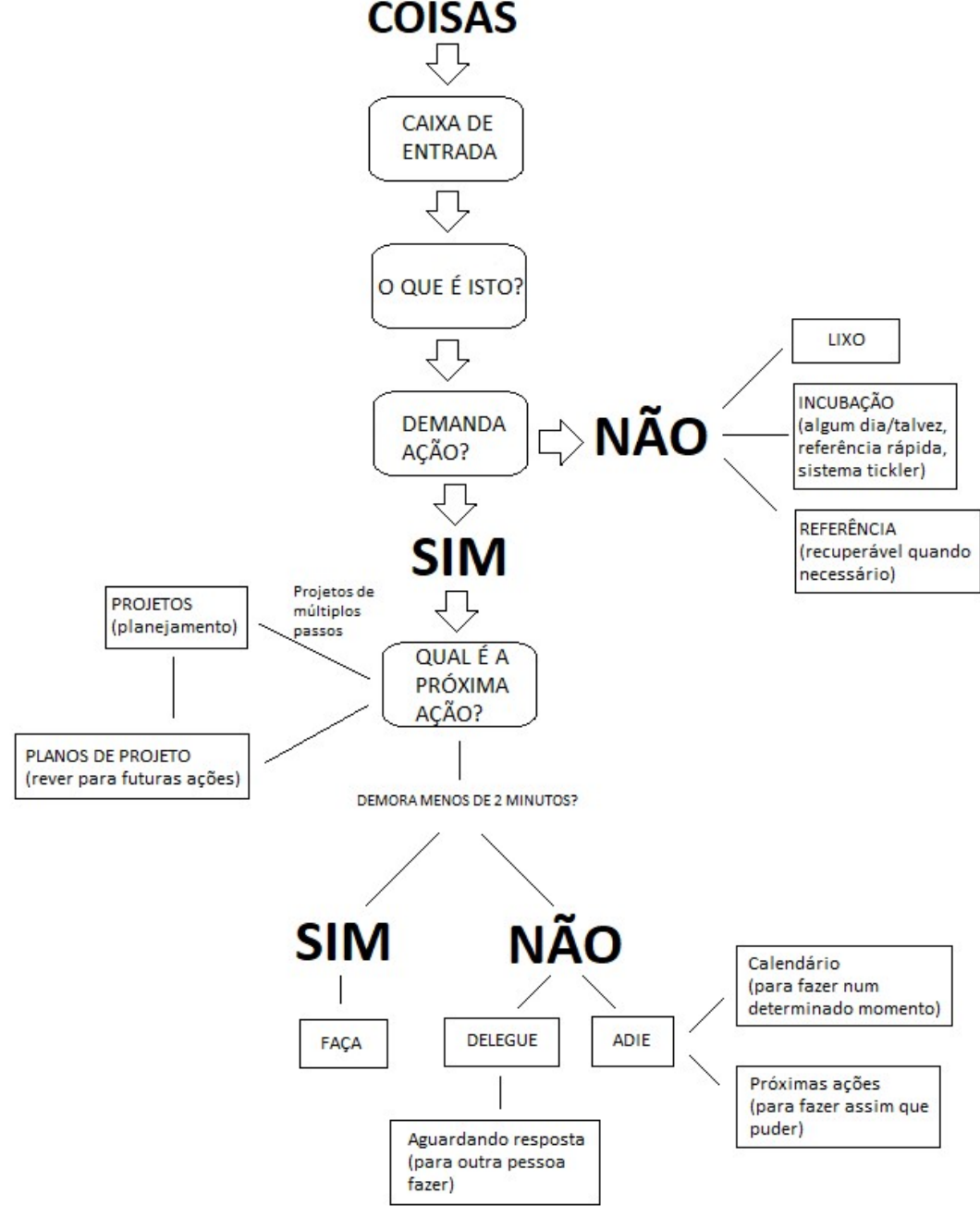

Fonte: Adaptado de Allen (2015, p. 67)

De maneira simplificada, como pode ser visto na Figura 2, todas as coisas que necessitam de alguma atenção devem ser colocadas na caixa de entrada. Este é o processo de CAPTURAR. 
Estando as coisas na caixa de entrada, a etapa que visa ESCLARECER traz duas perguntas: "o que é isso?" e "demanda alguma ação?".

Respondidas as perguntas, a etapa para ORGANIZAR as tarefas vai depender de um SIM ou NÃO sobre as coisas demandarem uma ação. Como mostra a Figura 2, aquelas que não requerem ação podem ser lixo, incubação ou referência. Já as tarefas que demandam ação devem ser categorizadas de acordo com o tempo: aquelas que levam menos de 2 minutos, devem ser feitas de imediato. Aquelas que demoram mais, precisam ser analisadas se serão delegadas ou adiadas para que sejam programadas.

REFLETIR sobre o que já foi feito e, principalmente, revisar o que está para fazer é um fator determinante para que as tarefas sejam cumpridas. Allen (2015) afirma que um fator crítico para o sucesso é a revisão semanal de todos os itens da lista.

O passo seguinte é ENGAJAR. Os três modelos apresentados anteriormente nas seções 3.5.1, 3.5.2 e 3.5.3 ajudam ao usuário do método a decidir sobre quais ações deve tomar. Engajamento é o que fará as coisas acontecerem realmente, pois, como salienta Allen (2015), há sempre mais que fazer do que realmente o sujeito é capaz.

\subsection{O profissional multitarefa}

Na área da Computação existe uma palavra em inglês que não tem uma tradução perfeita em português, que é thrashing. Na prática, ela significa que são utilizados muitos recursos computacionais, como memória do computador, para fazer uma pequena quantidade de trabalho.

Denning (2017) apresenta algumas lições de como o Sistema Operacional (SO) do computador pode ensinar como o profissional de Tecnologia da Informação ( $\mathrm{TI}$ ) pode executar multitarefas sem thrashing. $\mathrm{O}$ autor se baseia no método GTD de David Allen e lança a seguinte pergunta: "Por que não exportar ideias sobre o gerenciamento de tarefas em um sistema operacional?" (DENNING, 2017, p. 32, tradução nossa).

Segundo Denning (2017) há três grandes problemas que dificultam ou impedem as pessoas de conseguirem executar multitarefas, como faz o computador. O primeiro deles é a mudança de contexto. O ambiente no qual estamos inseridos muda constantemente e as tarefas que precisamos realizar também. O segundo é o chamado problema da incerteza da escolha, pois, se há muitas tarefas importantes a serem realizadas, precisamos de muito tempo para tomar a decisão de qual deve ser prioritária. O último é a quantidade de recursos necessários para realizar cada tarefa, que podem ser de três tipos: recursos físicos, como livros e equipamentos; recursos digitais como arquivos, imagens ou sons e recursos mentais, como coisas que precisam ser lembradas para a execução da tarefa.

Para a execução de multitarefas no SO do computador o autor propõe que seja realizada conforme a Figura 3, idealizada com base na proposta do método GTD.

Figura 3 - Controle de Tarefas no Sistema Operacional (SO)

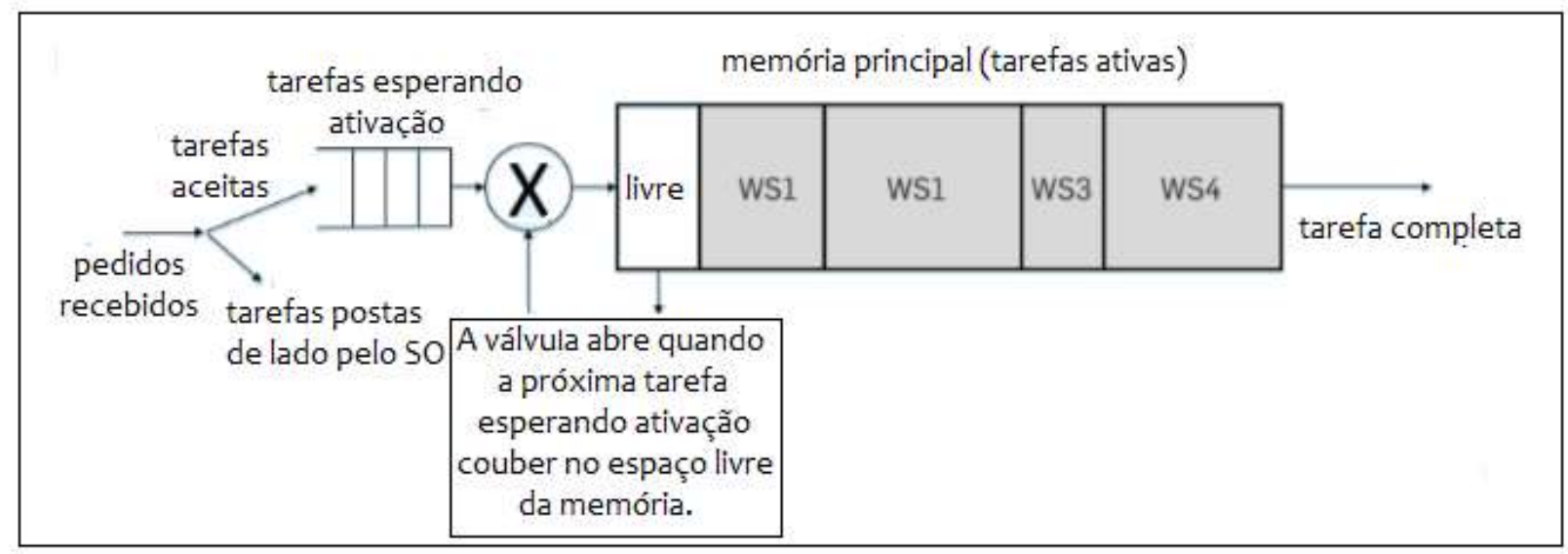

Fonte: Denning (2017, p. 34, tradução nossa)

As tarefas na caixa de entrada são classificadas como "tarefas aceitas" ou "tarefas postas de lado pelo SO". Para as primeiras, elas são colocadas em uma fila intitulada "tarefas esperando ativação". A válvula é aberta quando a primeira tarefa que estiver esperando ativação couber no espaço livre da memória.

Quando entra na memória, a tarefa vai receber espaço para execução conforme suas demandas, em WS1, WS2, WS3 e WS4, até que ela seja completada. 
Denning (2017) faz analogia deste sistema multitarefa do computador com a atividade humana, mesmo reconhecendo que a analogia não é perfeita. $O$ autor traz as seguintes lições do SO para o humano:

1. O fato de reconhecer que cada tarefa precisa de uma quantidade livre de espaço para entrar na memória é o mesmo que dizer que para o ser humano executar uma tarefa ele precisa de uma quantidade de recursos disponíveis, sejam eles físico, digital ou mental.

2. É necessário tempo para a execução da tarefa.

3. Algumas tarefas precisam ser mantidas de lado, até que se tenha a capacidade de lidar com elas.

4. Quando um conjunto de tarefas está no espaço de trabalho (WS1, WS2, WS3, WS4) ele deve ser protegido de outras tarefas. Se outras entrarem em execução, elas podem não ter mais espaço para que sejam realizadas.

5. Se forem assumidas mais tarefas que a capacidade, corre-se o risco de thrashing.

6. Interrupções temporárias podem causar perda de parte do trabalho ou mesmo demora na retomada.

Por fim, Denning (2017) lembra que se você estiver com mais tarefas que consegue fazer, é o caso de pedir ajuda, negociar prazos, adquirir mais recursos ou mesmo cancelar tarefas menos importantes.

\section{FERRAMENTAS DE GERENCIAMENTO DE TEMPO E PRODUTIVIDADE}

Para as pessoas, o acesso simultâneo às diversas informações pessoais e profissionais desencadeou vários dilemas, por exemplo, como organizar e gerir suas tarefas do dia a dia? Como gerir as diversas informações pessoais e profissionais adquiridas todos os dias? Para Barbosa $(2012$, p. 65) "os desafios da organização sempre existiram e o avanço da tecnologia acrescentou novas exigências a esse quadro. Quantos e-mails você recebe por dia? ".

Como resposta a este novo cenário de acúmulo de tarefas, sobretudo profissionais, que vivemos atualmente, foram criadas várias ferramentas tecnológicas essenciais que auxiliam as pessoas e organizações, como por exemplo Trello, Evernote, Toodledo, Asana, Slack, entre outras.

Neste artigo são abordadas duas ferramentas que implementam o método GTD, o Trello e Evernote.

\subsection{Trello}

Na busca por qualidade no desempenho do trabalho e até mesmo nas tarefas do dia a dia, existem, conforme apontado anteriormente, inúmeras ferramentas informatizadas que podem dar apoio nesse quesito.

Como apresentado nesse trabalho, o método GTD permite que seja feita a gestão de tarefas, organizando-as de forma que a força e tempo necessários para que se cumpra tais atividades sejam reduzidos, diminuindo o stress ao cumprir obrigações (CASTELLI, 2017). O método GTD contribui para organização do trabalho, documentos ou até mesmo eventos rotineiros.

O Trello é uma ferramenta que tem como principal característica a versatilidade de ser adaptável de acordo com a necessidade do usuário. Seu uso pode ser individual ou em grupo. Com a criação de um perfil na ferramenta, o usuário pode integrar inúmeros grupos diferentes, facilitando seu acesso a ferramenta através de um login único para todas as suas atividades. Além do mais, o Trello permite ser personalizado escolhendo papel de fundo, avatar, entre outros.

O cadastro na ferramenta é gratuito e atende muito bem funções básicas de gerenciamento de tarefas. Para atividades mais detalhadas e integrações com outras ferramentas de gestão, suporte diário entre outras atribuições é necessário o pagamento de uma taxa por usuário que varia de $\$ 9,90$ a $\$ 20,83$ dólares mensais.

Apresentado em inúmeros idiomas, o Trello se comunica muito fácil com o usuário através de boa navegabilidade, quase que intuitiva, não sendo necessário nenhum plugin adicional para seu uso. Através de boards (quadros) a ferramenta, já na sua tela inicial, separa suas atividades em nível macro e dentro de cada board permite separar a tarefa em subtarefas e por sua vez acaba por criar também uma estrutura analítica de tarefas. Neste processo é possível dividir toda obrigação determinada em partes mínimas que podem ter dependências entre si, bem como acompanhar o desenvolvimento de cada etapa.

A Figura 4 apresenta exemplos dos boards distribuídos por setores, de forma macro. 
Figura 4 - Interface do Trello

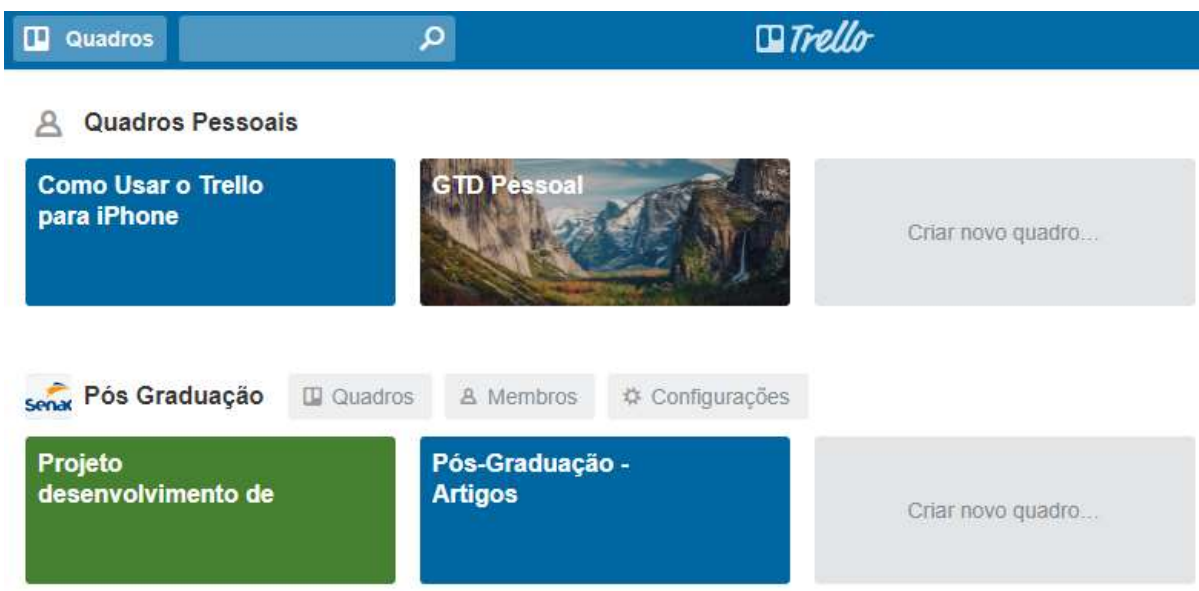

Fonte: Elaborado pelos autores (2017)

Dentro de um board, como mostrado na Figura 5, as atividades são divididas por cards (cartões) que por sua vez pode ser subdividido por inúmeros marcadores, opções de checklist (lista de verificação) entre outros.

Figura 5 - Divisão por cards

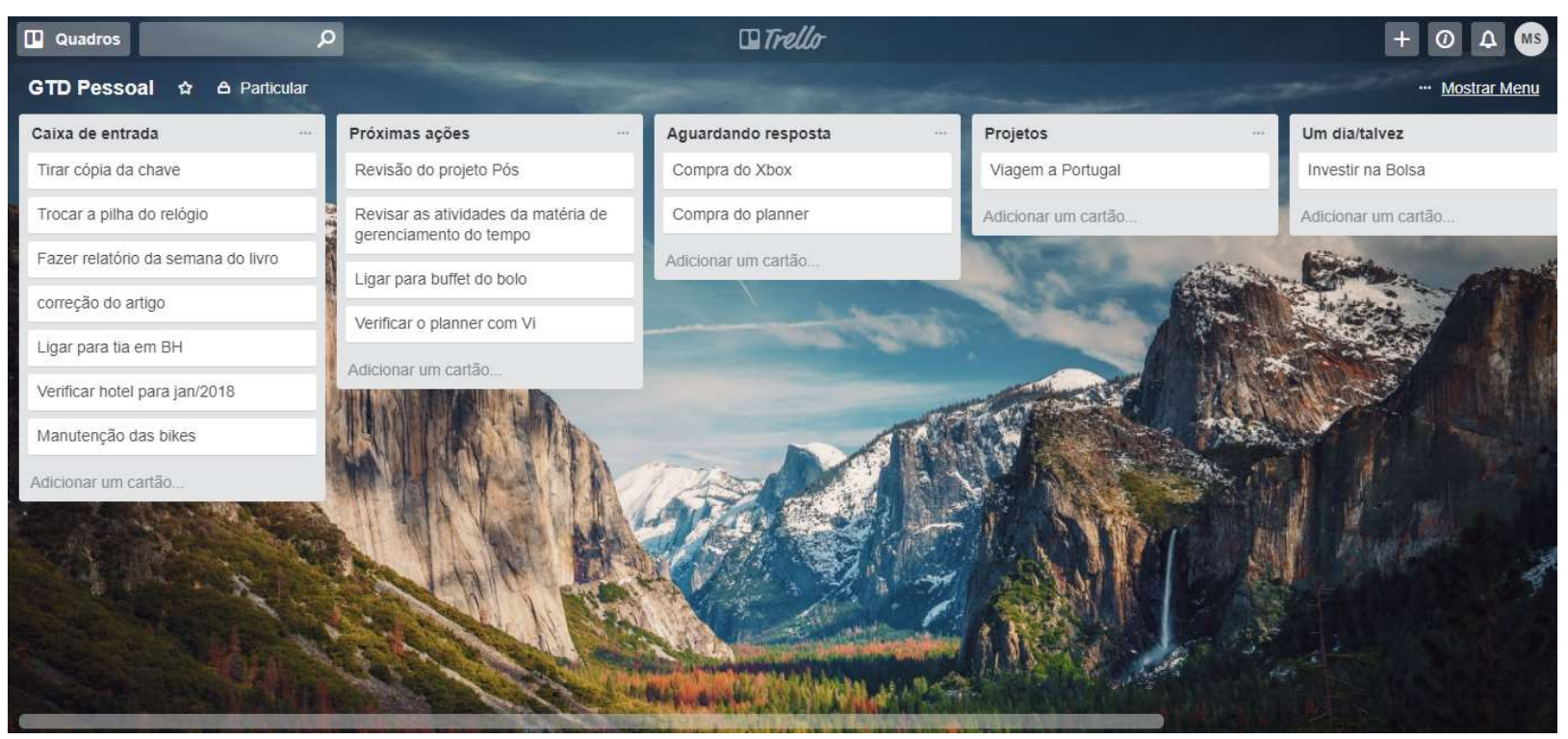

Fonte: Elaborado pelos autores (2017)

A atualização destes processos é simples e as atividades podem ser levadas para uma próxima etapa apenas arrastando o card, outra facilidade oferecida pelo Trello.

Por fim, temos o exemplo de um card dividido por cheklist, como ilustra a Figura 6. 
Figura 6 - Cheklist do Trello

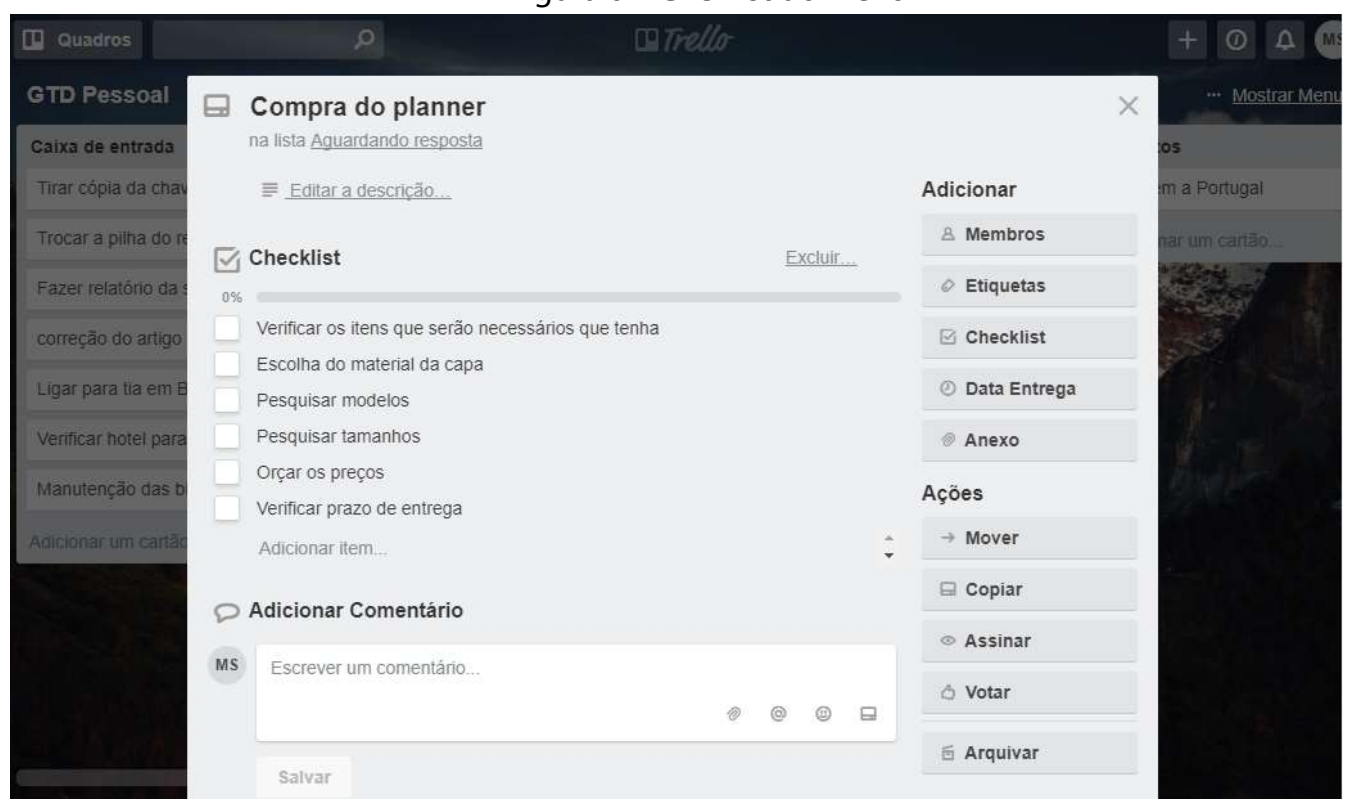

Fonte: Elaborado pelos autores (2017)

Todos os elementos do Trello podem ser nomeados de acordo com a necessidade do usuário, aumentando a usabilidade do sistema para gerenciar qualquer processo. Além disso, o Trello permite que qualquer usuário cadastrado na ferramenta possa ser incluido em um board específico, não sendo necessária a criação de inúmeros usuários para uma mesma pessoa. Este requisito é de extrema importância para gestão de equipes. Ao liberar acesso ao boardo gerente do projeto pode atribuir funções (cards) específicas para cada usuário, sendo possível incluir mais de uma pessoa por card.

As possibilidades de comunicação não param por aí, pois é possível deixar notas nas atividades e taguear(marcar com etiqueta) os responsáveis. Dessa forma, todos os chamados são notificados por e-mailo que acarreta na melhoria da comunicação entre as partes.

O Trello é uma ferramenta que atende às características definidas pelo método GTD e juntos fluem muito bem no desenvolvimento da gestão do seu dia a dia (SISI, 2017).

Com as funcionalidades já citadas é possível identificar e organizar as atividades por boards, cards, checklists e notificações, pois esses itens auxiliam diretamente nas propostas oferecidas pelo GTD, organizando o dia a dia por funções e prioridades.

Sendo usado individualmente ou em equipes, o Trello atende de forma satisfatóra as necessidades do usuário que pretende organizar suas funções diárias, através de simplicidade e com layout interativo.

\subsection{Evernote}

Evernote é um aplicativo capaz de organizar notas e/ou projetos pessoais, estudantis e profissionais. É importante salientar que não existe um método exclusivo e nem uma maneira correta de utilizar o Evernote. O aplicativo é fácil de usar pois apresenta uma interface agradável e simples, com a possibilidade de instalar em vários dispositivos (celular, tablete notebook).

Este aplicativo oferece vantagem para pessoas que recebem grandes volumes de informações e tarefas no seu dia a dia pois permite criar e ordenar anotações pessoais e profissionais, e possui espaço para trabalhos colaborativos. Além disso, na ferramenta é possível compartilhar, transformar e editar as anotações e tarefas de forma simples, além de oferecer a possibilidade de guardá-las em uma conta do Google Drive ou dispositivos eletrônicos.

Apesar das vantagens citadas, o Evernote apresenta também algumas desvantagens, entre elas, possui um design minimalista, não permite personalização, não possui "estado" para as tarefas, entre outros.

Existem três versões do aplicativo: Evernote Basic: gratuito, Evernote Plus por $\$ 34,99$ ao ano e Evernote Premium por $\$ 69,99$ ao ano. As versões pagas têm maiores benefícios como mais espaço de armazenamento, número ilimitado de dispositivos, possibilidade de acesso aos cadernos e notas offline e possibilidade de salvar e-mails no Evernote.

Conforme destacado anteriormente, o aplicativo desfruta de múltiplas maneiras de organizar os dados, sendo as principais: 
- A identidade principal do Evernote é a nota. Dentro de uma nota você pode armazenar textos, áudios, vídeos, imagens e arquivos em geral;

- Para organizar as suas notas, o Evernote permite a criação de cadernos. Cada caderno é a união de várias notas;

- E, por fim, para ajudar a catalogar suas notas, você também pode criar etiquetas (ou tags).

A Figura 7 apresenta a interface do Evernote, e a Figura 8 ilustra o uso da ferramenta na implementação do método GTD.

Figua 7 - Interface do Evernote

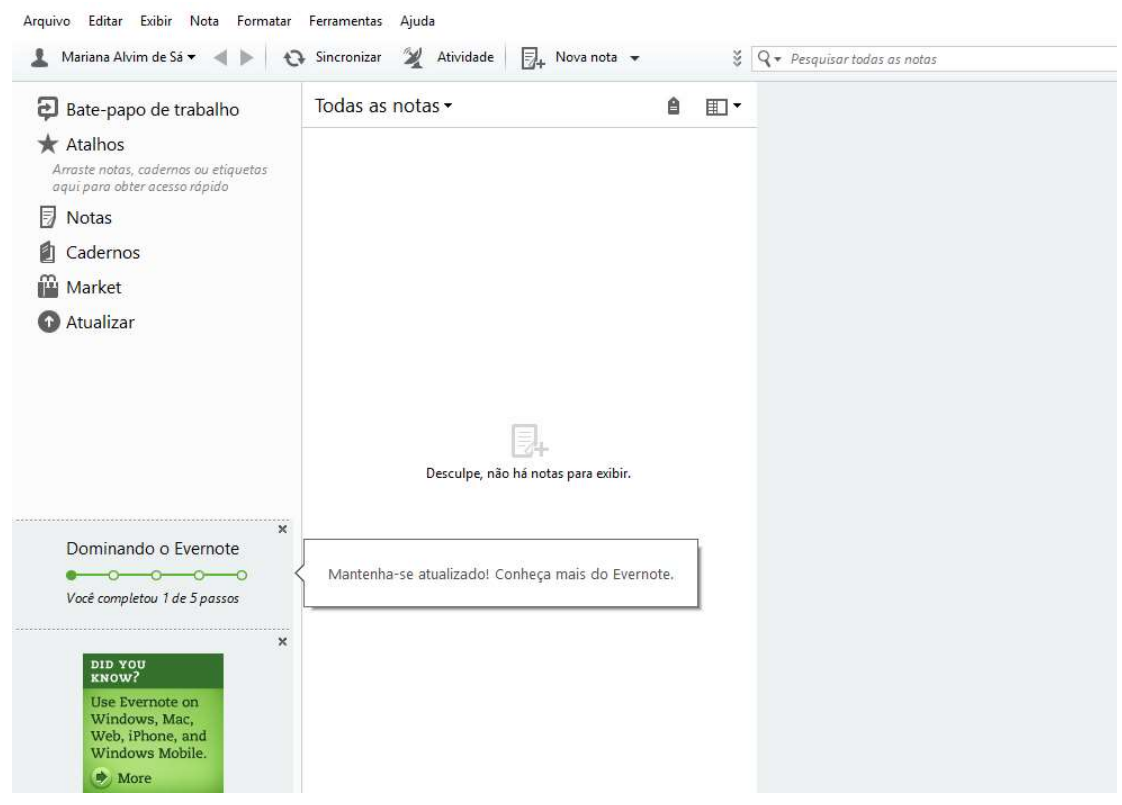

Fonte: Elaborado pelos autores (2017)

Figura 8 - O Método GTD no Evernote

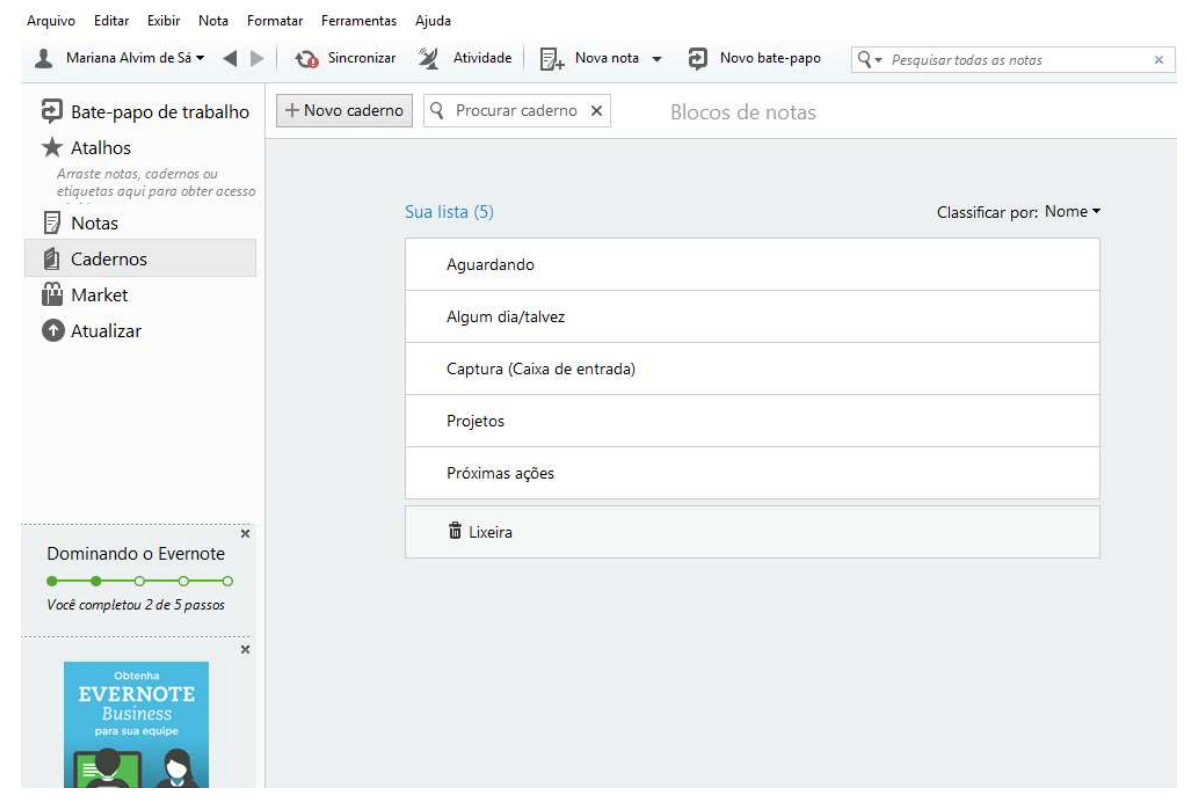

Fonte: Elaborado pelos autores (2017)

Conforme apresentado na Figura 8, a ideia básica de implementação do método GTD no Evernote é simples, porque são criados cadernos (notebooks) para cada elemento classificado na fase de organização. Certamente, a parte mais complexa não está reservada à criação das tarefas no Evernote, mas à observação das etapas do método em si. 


\subsection{Sugestões para escolha da ferramenta}

Nos dias atuais, as tecnologias da informação e comunicação, ao mesmo tempo que permitem que as tarefas possam ser executadas de forma mais rápida, trouxeram problemas, como o acúmulo delas, que obrigaram as pessoas a desenvolver ferramentas de produtividades para auxiliar nas tomadas de decisões e na organização e gestão das tarefas do dia a dia. Desse modo, com inúmeras ferramentas disponíveis no mercado, surge uma questão: como escolher uma ferramenta? Este aspecto também é elucidado por Rigby (2009, p. 5) que diz "ao longo das últimas décadas, ferramentas de gestão se tornaram comuns na vida das empresas [...], mas como identificar as ferramentas mais apropriadas para os desafios de sua organização?".

No presente artigo, que apresenta o método GTD, duas ferramentas que permitem sua aplicação foram apresentadas: Evernote e Trello. A seguir serão abordadas algumas sugestões apontadas por Karlson (2017) que podem auxiliar na escolha da ferramenta para ser utilizada junto ao método GTD. Vale ressaltar que, além das sugestões aqui descritas, a ferramenta precisa atender dois quesitos importantes: ser adequada às reais necessidades do usuário e ser adaptável ao seu ambiente de trabalho.

A seguir destacam-se alguns itens sugeridos por Karlson (2017) para auxiliar na seleção das ferramentas utilizadas:

- Trabalho colaborativo - A ferramenta deve possibilitar a organização de trabalho em equipe, ou seja, os membros podem gerenciar as tarefas;

- Custo - Os preços das ferramentas variam de acordo com as versões;

- Língua - A ferramenta precisa suportar a língua de melhor entendimento ao usuário;

- Layout - A ferramenta precisa possuir uma interface agradável, simples e de fácil uso;

- Suporte - Uma característica importante é possuir um canal de suporte técnico;

- Integração - Outra característica útil é permitir a integração com outras ferramentas;

- Classificação - Possuir uma reputação excelente na internet;

- Sincronização - Possibilitar o armazenamento dos dados na nuvem;

- Compatibilidade - É necessário saber em quais sistemas a ferramenta funciona.

No caso específico das ferramentas que implementam o método GTD aqui apresentadas, o Trello e o Evernote, é notável que ambas apresentam características e usabilidades muito semelhantes, diferenciando-se apenas pelo layoute valores caso se opte pelas versões pagas. Como não existe regra para a escolha de ferramentas para o método GTD, a decisão depende apenas das necessidades e gosto do usuário.

\section{CONCLUSÃO}

Este trabalho respondeu ao seu objetivo, apresentando as características e como funciona o método GTD, a relação com gerenciamento do tempo e produtividade, através, principalmente, da pesquisa bibliográfica, conforme proposta metodológica do artigo, com a visão de alguns estudiosos/especialistas do tema. Foram apresentados também softwares que podem ser utilizados como ferramentas que auxiliam na implementação do método GTD finalizando com algumas sugestões do autor Karlson (2017) para auxiliar na escolha da ferramenta.

O estudo apresenta de forma clara e sintética a necessidade que o método atende, assim como sua aplicabilidade em diversas situações, estas que permeiam entre fatos cotidianos até as mais complexas, como a rotinas de trabalhos e até mesmo projetos específicos.

Ao apresentar cada etapa, o leitor confere como funciona o método, exemplos práticos de aplicação do método, exercícios de observação e conclusão dos processos, assim como a importância de alguns detalhes.

Apresenta-se também ferramentas que possibilitam a aplicação do método GTD através de sofwares, que podem ser gratuitos ou pagos dependendo do modelo e funcionalidades desejadas.

A análise das ferramentas escolhidas, Trello e Evernote, demonstra a necessidade de organização e apresenta funcionalidades capazes de facilitar a vida do usuário. Através de itens básicos de organização, ambas apresentam funcionalidades que são diretamente ligadas a algumas etapas do método e atendem as necessidades básicas deste processo provando ser eficaz quanto à seu uso na implementação do método.

Por fim, é possível visualizar e fazer uma conexão método GTD - gerenciamento do tempo - produtividade, tendo o artigo ofertado uma contribuição aos meios de pesquisas mais uma ferramenta que pode auxiliar no gerenciamento de tempo e produtividade: o método GTD. Durante as pesquisas foi extremamente difícil localizar um trabalho científico (artigos, teses ou dissertações) que tratasse de gerenciamento de tempo ou produtividade de 
forma que não fosse atrelado a uma área específica como indústria, agronomia, saúde e outras mais. Esse artigo não trata de uma área específica, trata sobre ser produtivo, gerenciar atividades, tempo, de forma saudável, sem estresse e com uma ferramenta que facilite o processo.

\section{REFERÊNCIAS}

ALLEN, David. Getting things done: A arte de fazer acontecer. Rio de Janeiro: Elsevier, 2001.

ALLEN, David. A arte de fazer acontecer. Rio de Janeiro: Sextante, 2015.

BARBOSA, Christian. A tríade do tempo. Rio de Janeiro: Sextante, 2012.

CASTELLI, Ian. Trello: como esta ferramenta pode ajudar você a organizar a sua vida. 2015. Disponível em: <https://www.tecmundo.com.br/organizacao/75128-trello-ferramenta-ajudar-voce-organizar-vida.htm> Acesso em: 08 out. 2017.

DEMO, Pedro. Introdução à Metodologia da Ciência. 2. ed. São Paulo: Atlas, 1985.

DENNING, P. J. Multitasking Without Thrashing. Communications of the ACM, v. 60, n. 9, p. 32-34, Sept. 2017.

GERHARDT, Tatiana Engel; SILVEIRA, Denise Tolfo (Org.). Métodos de pesquisa. Coordenado pela Universidade Aberta do Brasil - UAB/UFRGS e pelo Curso de Graduação Tecnológica - Planejamento e Gestão para o Desenvolvimento Rural da SEAD/UFRGS. Porto Alegre: Editora da UFRGS, 2009.

GIL, Antônio Carlos. Como Elaborar Projetos de Pesquisa. 4. ed. São Paulo: Atlas, 2002.

GIL, Antônio Carlos. Métodos e Técnicas de Pesquisa Social. 6. ed. São Paulo: Atlas, 2008.

GODINHO, Thais. Vida organizada: como definir prioridades e transformar seus sonhos em objetivos. São Paulo: Gente, 2014.

GODINHO, Thais. Método GTD: potencialize a sua produtividade aplicando essa metodologia em seu dia a dia. 2017. Disponível em: <http://br.blog.trello.com/metodo-gtd/>. Acesso em: 02 out. 2017.

KARLSON, Karola. How to find the best project planning software? 2016. Disponível em: <https://www.scoro.com/blog/choosing-project-planning-software/>. Acesso em: 11 out. 2017.

LEVITIN, Daniel J. A mente organizada: como pensar com clareza na era da sobrecarga de informação. Rio de Janeiro: Objetiva, 2015.

MARCON, Marcos. GTD: conheça o método de produtividade mais famoso do mundo. 2015. Disponível em: <http://blog.wmw.com.br/gtd-conheca-o-metodo-de-produtividade-mais-famoso-do-mundo/ >. Acesso em: 21 nov. 2017.

MARCONI, Marina de Andrade; LAKATOS, Eva Maria. Fundamentos de Metodologia Científica. 5. ed. São Paulo: Atlas, 2003.

MORITZ, G. O. et al. A prospecção de cenários nas universidades: variáveis portadoras de futuro e a trajetória estratégica da UFSC para 2022. In: COLÓQUIO INTERNACIONAL SOBRE GESTÃO UNIVERSITÁRIA NA AMÉRICA DO SUL, 10., 2010, Mar Del Plata. Anais... Mal Del Plata: Universidad Nacional de Mar Del Plata, 2010.

RIGBY, Darrell J. Ferramentas de gestão: um guia para executivos. São Paulo: Bain \& Company, 2009.

SISI, Marcia Cristina. Como utilizar o Trello para aplicar o GTD. 2017. Disponível em: <http://www.calldaniel.com.br/blog/como-utilizar-o-trello-para-aplicar-o-gtd>. Acesso em: 07 out. 2017. 